\title{
Bulanık Bilişsel Haritalar Kullanılarak Yeşil Tedarik Zinciri Yönetimi İçin Bir Değerlendirme Modeli
}

\author{
${ }^{1}$ Özer Uygun, ${ }^{* 2}$ Enes Furkan Erkan, ${ }^{3}$ Halil İbrahim Demir \\ ${ }^{1,2,3}$ Sakarya Üniversitesi, Mühendislik Fakültesi, Endüstri Mühendisliği Bölümü, Sakarya,
}

\section{$\ddot{O} \mathbf{z}$}

Küresel 1sınmanın hızla arttığı günümüz dünyasında, teknoloji ve sanayinin de gelişime devam etmesiyle birlikte birçok sorun gün yüzüne çıkmaktadır. Bu sorunları azaltabilmek için çevreyi korumak, doğaya olabildiğince az zarar vermek gerekmektedir. Dünya'nın geleceği için kuruluşlara önemli görevler düşmektedir. Bu sebeple kuruluşlar artık her anlamda çevre dostu olan ve verimliliği de oldukça arttıran yeşil tedarik zinciri yönetimini (YTZY) uygulamaya başlamışlardır. Yeşil tedarik zinciri yönetiminin analitik olarak değerlendirilmesinin güç olması, işletmeler için önemli bir sorun teşkil etmektedir. Bu çalışma, işletmeleri yeşil tedarik zinciri yönetimi açısından değerlendirmeyi amaçlamaktadır. Değerlendirme için bulanık mantık ve bilişsel haritalar temelli Bulanık Bilişsel Haritalar (BBH) yöntemi kullanılmıştır. İlk olarak uzman görüşlerine göre yeşil tedarik zinciri yönetimini etkileyen faktörlerin ilişki haritası oluşturulmuştur. Daha sonra BBH tekniği ile faktörler arasındaki ilişki ağırlıkları belirlenmiştir. Belirlenen ağırlıklar BBH algoritmasına girdi olarak sunularak, oluşturulan üç senaryo için yeşil tedarik zinciri yönetimi açısından gelecekte öngörülen durumlar tespit edilmiştir. Böylelikle çeşitli çıkarımlar yapılabilmiş ve yeşil tedarik zinciri yönetiminin başarısı için üzerinde durulması gereken faktörler de belirlenmiştir.

Anahtar kelimeler: Bulanık Bilişsel Haritalar, Bilişsel Haritalar, Yeşil Tedarik Zinciri Yönetimi

\section{An Evaluation Model for Green Supply Chain Management Using Fuzzy Cognitive Maps}

\begin{abstract}
In today's world in which global warming increases rapidly, several problems are emerging based on development of technology and industry. The environment should be protected and the nature should be damaged as less as possible in order to decrease these problems. Companies have important missions for the future of the world. For this reason, organizations started to implement green supply chain management which is nature friendly in every sense and increase productivity. Analytically evaluation of green supply chain management is not easy which is a challenge for companies. The aim of this study is to evaluate companies with regard to green supply chain management. Fuzzy-logic and fuzzy cognitive maps techniques were used for the evaluation. First, relationship map of factors that affects green supply chain management are constituted. Then, weights of the relationships between the factors are calculated using fuzzy cognitive maps techniques. The weights obtained are used as inputs in fuzzy cognitive maps algorithm and anticipated conditions in terms of green supply chain management are evaluated for three scenarios. Thus, several arguments were developed and the most important factors are determined for the success of green supply chain management
\end{abstract}

Keywords: Fuzzy Cognitive Maps, Cognitive Maps, Green Supply Chain Management

\section{GİRIŞ}

Uzun seneler boyunca, işletmelerin yaydığı zararlı gazlar, doğaya bırakılan katı atıklar, sulara akıtılan kimyasal maddeler gibi olumsuz etkilerin dünyamızı kötü etkilemesi göz ardı edilmiştir. Ama sanayi ve teknoloji ilerledikçe bu sorunlar artık göz ard1 edilemeyecek seviyeye gelmiş ve 90'l1 yılların sonunda dünyanın nasıl temizleneceği konusunda uluslararası bağlayı çözümler aranmaya başlanmıştır. Buna bağlı olarak şimdiki 'çevresel duyarlılık çağı' kurumların endüstriyel gelişimlerini sürdürürken çevreyi de korumaları gerektiği yönünde hedefler sunmaktadır [1]. Sanayilerdeki baca gazlarının insan sağlığına daha az olumsuz etki edecek şekilde düzenlenmesi, kimyasal sanayideki zehirli atıkların minimuma indirgenmesi, kâğıt endüstrisinde kullanılan 
kâğıtların geri dönüşüme uygun olması gibi uygulamalar sektörel bazda çevreye daha duyarlı olabilmek adına yapılan bazı faaliyetlerdir. Kurumların çevre dostu olarak yaptığı çalışmalar, 'yeşil' sıfatıyla anılmaktadır.

Tedarik zinciri yönetimi, tedarikçiden son müşteriye kadar, bir dağıtım kanalının toplam akışını yöneten, bütünleştirici bir felsefedir [2]. Tedarik zinciri yönetimindeki tüm faaliyetlerin çevreye duyarlı hale getirilmesi yani yeşil yönetime göre tekrar düzenlenmesi halinde kurumlar da müşteriler de bu durumdan daha fazla memnun kalacaktır. Bunun sebebi, zorlaşan rekabet şartlarında kurumların diğerlerinden bir adım öne çıkmak için sosyal sorumluluk düşüncesi içinde, doğayı korumak adına yaptıkları çalışmalar karşılığında daha fazla tercih edilip maddi anlamda kazanç sağlayacak olmalarıdır.

Yeşil tedarik zinciri yönetimi, tedarik zincirinin yeşil yönetime ve tersine lojistiğe göre tekrar düzenlenmesiyle elde edilen bir yönetim şeklidir [3]. Yeşil tedarik zinciri yönetimi, stratejik kararlardan taktiksel kararlara kadar olumsuzlukları azaltır ve kontrol mekanizmasını güçlendirir, kaynak kullanımını azaltır, geri dönüşüme olanak sağlar ve kuruma her anlamda fayda sağlar. Yeşil tedarik zinciri faaliyetleri; yeşil pazarlama, yeşil satın alma, yeşil üretim, yeşil tasarım, yeşil lojistik olarak sıralanabilir.

Yeşil satın alma faaliyeti, yeşil tedarik zinciri yönetimindeki en önemli faaliyettir. Yeşil satın alma kararları, yeniden kullanılabilir, geri dönüştürülebilir ya da geri dönüşümü yapılmış malzemeleri satın alma faaliyetleridir. Satın alınacak ürünün çevresel tasarım spesifikasyonlarının olması ve iyi belirlenmesi gerekir [4]. Yeşil üretim, çevre etkileri düşük girdiler kullanan, yüksek verimliliğe sahip olan ve çok az veya sıfır atık içeren ve kirlilik oluşturmayan üretim süreçlerini kapsar. Bu tanımıyla yeşil üretim atık ve kirliliğin engellenmesi veya azaltılmasını, geri dönüşümü ve yeşil ürün tasarımını içeren faaliyetler çerçevesinde ele alınabilir [5]. Yeşil üretim, çevre etkileri düşük girdiler kullanan, yüksek verimliliğe sahip olan ve çok az veya sıfır atık içeren ve kirlilik oluşturmayan üretim süreçlerini kapsar. Bu tanımıyla yeşil üretim atık ve kirliliğin engellenmesi veya azaltılmasını, geri dönüşümü ve yeşil ürün tasarımını içeren faaliyetler çerçevesinde ele alınabilir [5]. Yeşil lojistik, lojistik kavramına ek olarak yenilenmeyen doğal kaynakların tüketimi, gaz emisyonu, gürültü kirliliği, zehirli ve zehirli olmayan çöplerin imha edilmesi gibi konulara yoğunlaşarak katlanılabilir bir maliyetle tüketiciye son ürünü ulaştırmayı hedeflemektedir [6]. Tersine lojistik, "değerinin geri kazanılması veya uygun şekilde yok edilebilmesi için ürünün ve bilginin tüketim noktasından orijin noktasına doğru akışının etkinleştirilmesi için yapılan planlama, uygulama ve kontrol aktiviteleridir [7].

Şirketler ve organizasyonlar çevresel riskler konusunda bilinçlendikçe, karbon yönetimi kurumsal sosyal sorumluluk ve performans yönetimi için daha fazla önem kazanmaktadır. Karbon yönetimi şirketlerin emisyonlarını azaltmak ve potansiyel enerji verimliliği projelerini tespit etmek için de bir araç olmaktadır. İklim değişikliğine yol açan malzeme ya da hareketler genellikle şirket ya da organizasyon için en büyük maliyet kalemleri arasında yer almaktadır. Bunların azaltılması hem karbon salınımının azaltılması hem de maliyetlerin düşürülmesi anlamına gelmektedir. Karbon yönetimi operasyonel maliyetleri düşürmeye ek olarak tüketiciler gözünde marka değerini de artırmakta ve her iki nedenle de rekabet avantajı sağlamaktadır.

Küresel 1sınmanın hızla arttığı bu zamanlarda müşterilerin çevreyi koruma konusundaki hassasiyeti artmış ve talepleri de bu doğrultuda oluşmuştur. Bunun karşılığında firmalar hem kendi verimliliklerini artırmak hem de müşterilerini daha fazla memnun edebilmek amacıyla yeşil tedarik zinciri yönetimini uygulamaya başlamışlardır.

Bulanık bilişsel haritalama yöntemi, uzmanların dilsel ifadelerle belirttikleri fikirlerinin üyelik fonksiyonları yardımıyla sayısal ifadelere dönüştürülmesini sağlamaktadır. Yeşil tedarik zinciri yönetimi değerinin ne zaman dengeye ulaşacağına karar vermek için de sayısal ifadelerden ziyade uzman görüşlerinden yararlanılmıştır ve bulanık bilişsel haritalar bu konuda oldukça büyük bir kolaylık sağlamıştır.

$\mathrm{Bu}$ çalışmanın amacı, yeşil tedarik zinciri yönetiminin belirtilen faaliyetlerini uygulayan organizasyonların ne kadar süre sonra dengeye ulaşıp istenilen duruma geleceğini veya gelemeyeceğini bulanık bilişsel haritalama yardımıyla tespit etmektir.

Çalışmanın 2. bölümünde uygulama kısmında kullanılmış olan bulanık bilişsel haritalar yaklaşımı yer almaktadır. 3. bölümde ise yeşil tedarik zinciri yönetiminin $\mathrm{BBH}$ yöntemiyle değerlendirilmesine dair yorumlarda bulunulmuştur. 4. bölümde yeşil tedarik zinciri yönetiminde etkili olan faktörler analiz çalışmasıyla belirlenmiştir. Son olarak 5 . bölümde ise sonuç kısmı yer almıştır.

\section{YÖNTEM}

\subsection{Bulanık Bilişsel Haritalar (Fuzzy Cognitive Maps)}


Bulanık mantığın bilişsel haritalarda kullanılması bilişsel haritaların farklı alanlara daha kolay adapte edilmesini sağlamıştır. Kavramlar arası ilişkilerin sayısal ifadeler yerine bulanık kümelerle tanımlanması nitel bir model oluşturmakta ve uzmanların hassas sayısal ifadelerden kaçınarak uzmanlık alanındaki bilgileri basit dilsel ifadelerle sisteme aktarmasını sağlamaktadır. Metodu ön plana çıkaran özellikler; sistemin matematiksel denklemler yerine grafiksel olarak üyelik fonksiyonlarıyla temsil edilmesi, sistemin tanımlanmasında günlük konuşma dilinin kullanılmasıdır. Bu özellikler yabancı uzmanların metodu daha kolay ve doğru anlamasını sağlamakta ve metodun farklı alanlara uygulanabilme yetisini artırmaktadır.
$\mathrm{BBH}$, bulanık mantık ve bilişsel haritaların bir kombinasyonudur. Kompleks sistemler içindeki çoklu faktörler arasındaki nedenselliği belirten bir grafik yöntemdir [8].

BBH, sistemi bir bütün olarak ifade edebilmektedirler. İlgili alandaki bilgi sahibi uzmanlardan görüşleri alınarak sistem haritası oluşturulur. Haritanın kapsamı etkileşimlerin gösterilmesidir. BBH'ın en büyük avantajı eksik bilgi ile çalışabilmesidir. Eğer koşullarda herhangi bir değişiklik olursa, bu değişim kolayca sisteme yansitilabilmektedir [9].

Çeşitli alanlarda BBH yöntemi uygulanmaktadır. Tablo 1'de BBH yönteminin uygulandığı bazı alanlar gösterilmektedir.

Tablo 1. Bazı BBH Uygulama Alanları

\begin{tabular}{ccc}
\hline Referans & Uygulama Alanı & Çözüm Metodu \\
\hline$[10]$ & Politika ve Sosyal Bilimler & Modelleme, Politika Senaryoları \\
{$[11]$} & & Karar Destek Sistemi \\
{$[12]$} & Sağllk & Sinıflandırma \\
{$[13]$} & & Tahmin, Modelleme \\
{$[14]$} & Mühendislik & Modelleme \\
{$[15]$} & Yönetim & Karar Destek Sistemi \\
{$[16]$} & Üretim Sistemleri & Karar Destek Sistemi \\
{$[17]$} & & Karar Destek Sistemi \\
{$[18]$} & Çevre ve Tarım & Karar Destek Sistemi \\
{$[19]$} & Bilgi Teknolojileri & Karar Destek Sistemi \\
{$[20]$} & & Politika Senaryoları \\
\hline
\end{tabular}

Şekil 1'de basit bir BBH yapısı gösterilmektedir. Oklar, faktörler arasındaki nedenselliği göstermektedir. Okun ucunda bulunan faktör etkilenen faktörü göstermektedir. W, sistemdeki her faktör arasındaki ilişkinin etkileşim ağırlığını göstermektedir. Ağırlık ile ilgili üç durum olabilmektedir;
- $\quad \mathrm{C}_{\mathrm{i}}, \mathrm{C}_{\mathrm{j}}{ }^{\prime} \mathrm{yi}$ negatif olarak etkiler. Bunun anlamı eğer $C_{i}$ faktöründe pozitif/negatif yönlü bir artış olursa, $C_{j}$ 'de negatif/pozitif yönlü zıt bir artış olacaktır $(\mathrm{Wij}<0)$.

- $\mathrm{C}_{\mathrm{i}}$ ve $\mathrm{C}_{\mathrm{j}}$ birbirini etkilememektedir $(\mathrm{Wij}=0)$

- $\quad \mathrm{C}_{\mathrm{i}}, \mathrm{C}_{\mathrm{j}}{ }^{\prime} \mathrm{yi}$ pozitif olarak etkiler. Bunun

anlamı eğer $C_{i}$ faktöründe pozitif yönlü bir artış olursa, $\mathrm{C}_{\mathrm{j}}$ 'de $\operatorname{artacaktır}\left(\mathrm{W}_{\mathrm{ij}}>0\right)$.

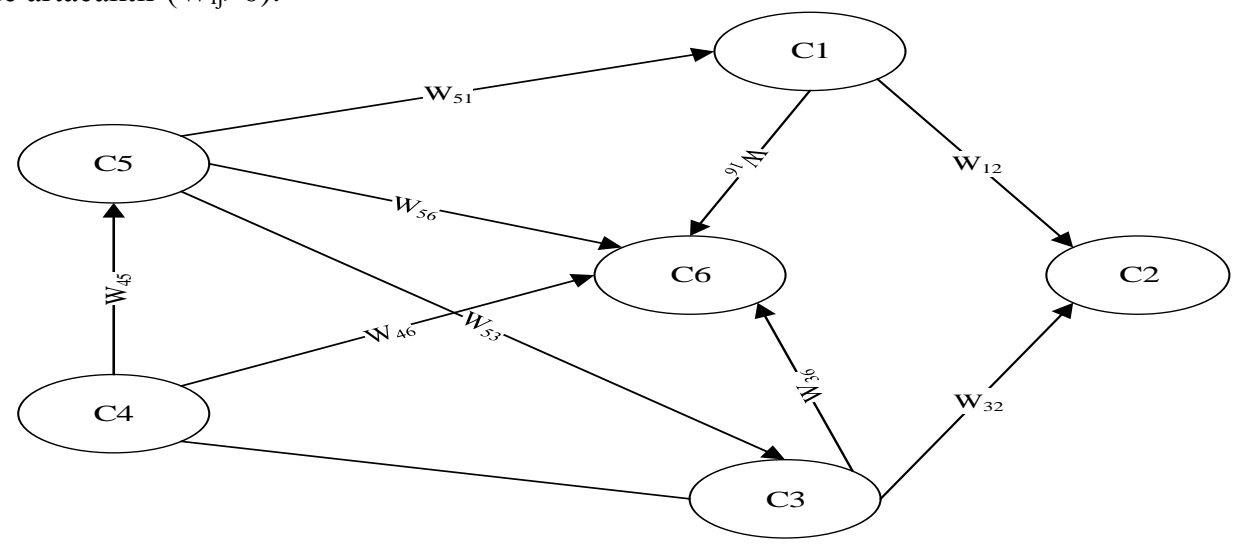

Şekil 1. Basit Bir BBH Yapısı 
Her $C_{i}$ kavramsal değişkeni için $A_{i}^{(k+1)}$ değeri, Kosko'nun 1986 yılında bulanık bilişsel haritalama yöntemi için kullandığı aktivasyon fonksiyonundan türetilmiş olan Denklem (1) ile bulunmaktadır. Bu çalışmada diğer aktivasyon fonksiyonlarından farklı olarak Denklem (1)'in seçilmesinin nedeni modeli en iyi ifade eden aktivasyon fonksiyonu olmasıdır:

$A_{i}^{(k+1)}=f\left(\left(2 \times A_{i}^{(k)}-1\right)+\sum_{j=1, j \neq 1}^{N} W_{j i} \times A_{j}^{(k)}\right)$

$\mathrm{A}_{\mathrm{i}}^{(\mathrm{k})}, \mathrm{C}_{\mathrm{i}}$ kavramsal değişkeninin $\mathrm{k}$ zamanındaki değerini; $\mathrm{A}_{i}{ }^{\left({ }^{+}+1\right)}, \mathrm{C}_{\mathrm{i}}$ kavramsal değişkenini etkileyen $\mathrm{C}_{\mathrm{j}}$ kavramsal değişkenlerinin $(\mathrm{k}+1)$ zamanındaki değerini; $W_{\mathrm{ji}}, \quad \mathrm{C}_{\mathrm{j}}$ kavramsal değişkeninden $\mathrm{C}_{\mathrm{i}}$ kavramsal değişkenine olan etki değerini; ve $f$ aktivasyon fonksiyonunu göstermektedir.

Bulanık Bilişsel Haritalarda biavelent, trivalent, sigmoid ve tanjant olmak üzere 4 çeşit eşik değer fonksiyonu kullanılmaktadır. Sigmoid ve tanjant fonksiyonları Denklem (2) ve (3)'te sirasiyla gösterilmiştir. $\mathrm{Bu}$ çalışmada değerleri 0 ile 1 arasında tutmak için Denklem 2'deki sigmoid fonksiyonu kullanılmıştır. Eğer modelde negatif değerler alabilen konseptler olsaydı, tanjant dönüşüm fonksiyonu da kullanılabilirdi. Tanjant eşik değer fonksiyonu, değerleri -1 ile 1 arasında tutmaktadır. X ile belirtilen değer formül (1)'den gelmektedir.

$f(x)=\frac{1}{1+e^{-\delta \times x}}$

$f(x)=\frac{e^{2 x}-1}{e^{2 x}-1}$

$\mathrm{Bu}$ çalışmada, yeşil tedarik zincirinin eğilimini değerlendirmek için dilsel değişkenler ile değerlendirme yapısına uyumlu BBH kullanılmıştır. İlgili alandaki her uzman kendi görüşünü Şekil 2'deki dilsel değişkenler ile belirtmiştir.

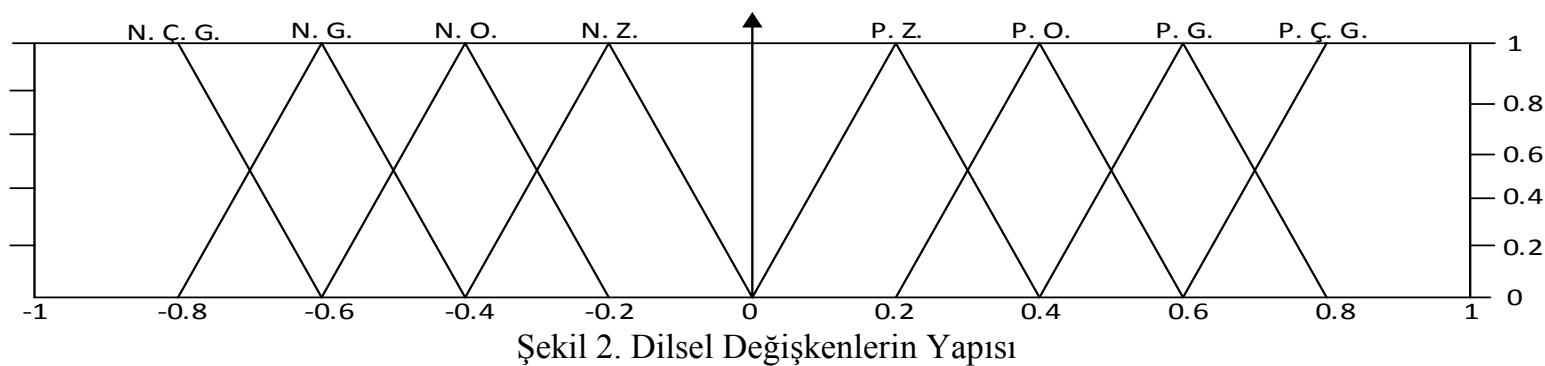

Birçok model karar vericilere sayısal veri kullanmak için gerekli imkanı sağlayamaz. BBH, dilsel değişkenler yapısıyla bu tür modelleri çözebilme yeteneğine sahip bir metottur. Dilsel değişkenler $[-1,1]$ aralığında değerler alabilmektedirler. Konseptler arasındaki etkinin gücünü, bulunduğu aralık belirlemektedir.

Şekil 2'de belirtilen yapıda sekiz adet etki dilsel değişkeni bulunmaktadır (Negatif çok güçlü, negatif güçlü, negatif orta, negatif zayıf, pozitif zayıf, pozitif orta, pozitif güçlü, pozitif çok güçlü). Dilsel değişken üyelik fonksiyonlarının sabit bir yapısı bulunmamaktadır. Dilsel değişkenlerin sayısı karar vericilerin inisiyatifi altındadır. Fakat unutulmamalıdır ki çok fazla sayıda olan dilsel değişken, konseptler arasındaki etkinin tanımlanmasını zorlaştıracaktır.

\subsection{BBH Çıkarım Algoritması (Inference Algorithm of FCMs)}

Sistem yapısı oluşturulduktan sonra, BBH algoritması aşağıdaki gibi çalıştırılır;

Adım 1: Mevcut sistem durumunu gösteren
Adım 2: (1) ve (2) formülleri uygulanarak $\mathrm{A}^{(\mathrm{k}+1)}$ elde edilir.

Adım 3: $\quad$ Elde edilen $\mathrm{A}^{(\mathrm{k}+1)}$, bir sonraki iterasyonun yeni $\mathrm{A}^{(\mathrm{k})}$ vektörüdür.

Adım 4: $\quad$ Adım 2 ve $3 \quad \mathrm{~A}^{(\mathrm{k}+1)}-\mathrm{A}^{(\mathrm{k})}<0,001$ eşitliği sağlanana kadar tekrar edilir.

Her $\mathrm{A}^{(\mathrm{k}+1)}$ daha önceden uzmanlar tarafindan tanımlanmış olan $(\mathrm{k}+1)$ zamanındaki sistemin durumunu göstermektedir.

\section{UYGULAMA}

$\mathrm{Bu}$ çalışmada ilk olarak yeşil tedarik zinciri yönetiminin faaliyetleri belirlenmiş ve uzmanlar tarafından bu faaliyetler için bir ilişki haritası oluşturulmuştur. Faaliyetler Tablo 2'de gösterilmiştir.

Daha sonra ilişkiler üç uzman tarafindan yorumlanmış bulanık mantık yardımıyla; ağırlık merkezi yöntemi kullanılarak sayısal değerler elde edilmiştir. Elde edilen bu değerler $\mathrm{BBH}$ algoritmasına girilmiştir ve sonuçlar elde edilmiştir. 
Tablo 2. YTZY Modeli Konseptleri

\begin{tabular}{cc}
\hline Kod & Konsept İsmi \\
\hline C1 & Yeşil Tasarım \\
C2 & Yeşil Satın Alma \\
C3 & Yeşil Lojistik \\
C4 & Yeşil Üretim \\
C5 & Yeşil Pazarlama \\
C6 & Yönetmeliklerin Bilinmemesi \\
C7 & Tersine Lojistik \\
C8 & Karbon Yönetimi \\
C9 & Gelenekselci Yaklaşım \\
C10 & YTZY Performansi \\
\hline
\end{tabular}

Yeşil tasarım, bir ürünün sadece atık değerinin çevreye etkileriyle ilgilenmeyip, ürünün yaşam döngüsü boyunca bir bütün olarak çevreye etkisiyle ilgilenen bir konsepttir.

Yeşil satın alma kararları, yeniden kullanılabilir, geri dönüştürülebilir ya da geri dönüşümü yapılmış malzemeleri satın alma faaliyetleridir.

Yeşil lojistik, lojistik kavramına ek olarak yenilenmeyen doğal kaynakların tüketimi, gaz emisyonu, gürültü kirliliği, zehirli ve zehirli olmayan çöplerin imha edilmesi gibi konulara yoğunlaşarak katlanılabilir bir maliyetle tüketiciye son ürünü ulaştırmayı hedeflemektedir.

Yeşil üretim, çevre etkileri düşük girdiler kullanan, yüksek verimliliğe sahip olan ve çok az veya sıfır atık içeren ve kirlilik oluşturmayan üretim süreçlerini kapsar.

Yeşil pazarlama, ürünün ilk halinden müşteriye ulaşıncaya kadar olan süreçlerin çevreye duyarlı olmasıyla ilgili süreçleri kapsar.

Yönetmeliklerin bilinmemesi, firmanın çevreyle ilgili uyulması gereken prosedürlerden habersiz olmamışıyla ilgili süreci kapsar.

Tersine lojistik, lojistik kavramına ek olarak yenilenmeyen doğal kaynakların tüketimi, gaz emisyonu, gürültü kirliliği, zehirli ve zehirli olmayan çöplerin imha edilmesi gibi konulara yoğunlaşarak katlanılabilir bir maliyetle tüketiciye son ürünü ulaştırmayı hedeflemektedir.

Karbon yönetimi, firmanın üretim aşamasında ürünün çevreye olan karbon salınımını azaltma süreçlerini kapsar. Karbon salınımının yüksek olması, YTZY açısından kötü bir durumdur.

Gelenekselci yaklaşım, firmanın geçmiş alışkanlıklarından kopamaması ve çevre için uyulması gereken kurallar için değişim yaşamamasını ifade etmektedir.

Şekil 3'de uzmanlar tarafından oy birliği ile yeşil tedarik zinciri yönetimini etkileyen konseptlere ait modelin durumunu ortaya koyan bir ilişki haritası görülmektedir.

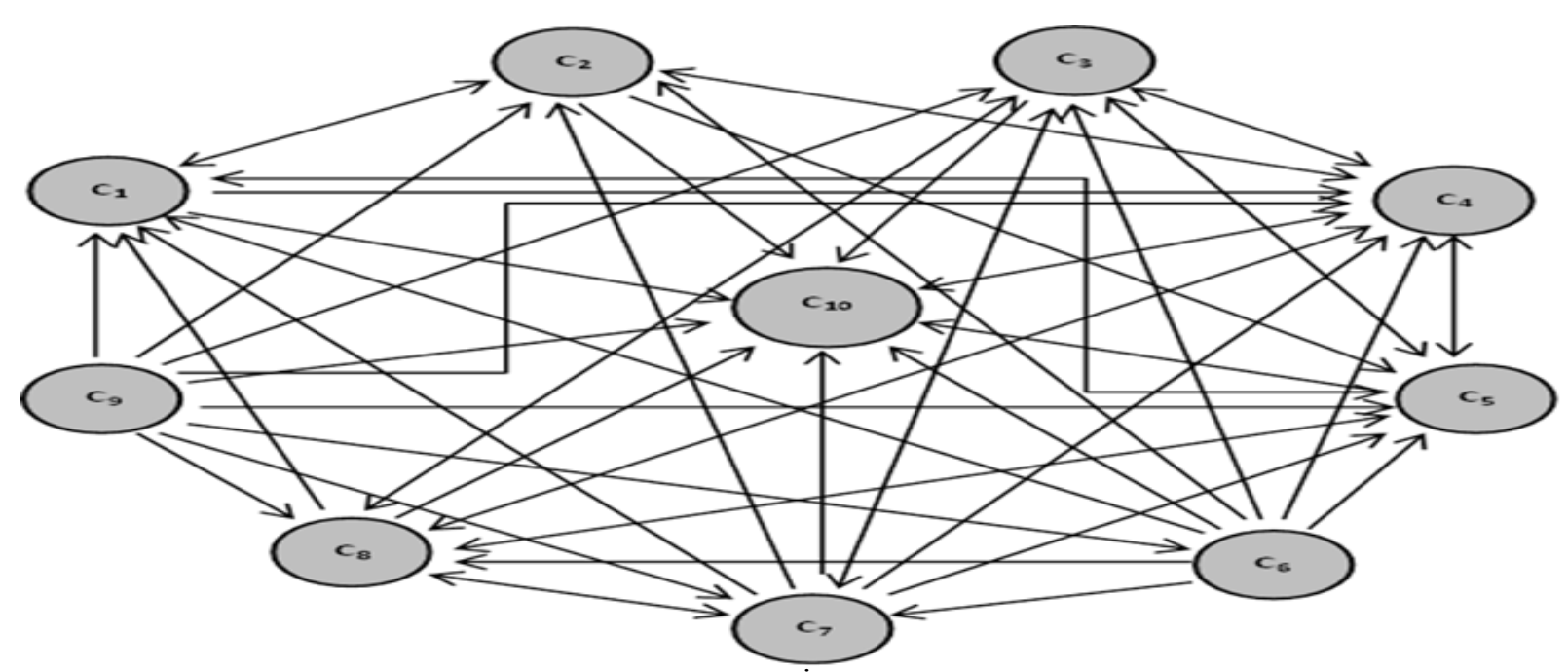

Şekil 3. YTZY İlişki Haritası

Daha sonra konseptler arasındaki ilişkilerin ağırlıklarının bulunabilmesi için uzmanlar ayrı ayrı Şekil 2'deki dilsel değişkenleri kullanarak yorumlar yapmışlardır. IF-THEN kurallarıyla etkiler belirlenmiştir. Ortak bir etki ağırlığ1 belirleyebilmek için üyelik fonksiyonu değerleri toplanmış ve ağırlık merkezi yöntemiyle ağırlık değerleri bulunmuştur. Bulunan ağırlık değerleri Tablo 3'de gösterilmiştir.
Ağırlık merkezi hesaplanırken Şekil 2'deki üyelik fonksiyonundan faydalanılır. Dilsel ifadelere karşılık gelen değerlerin ortalamasının alınmasıyla hesaplanır. Aşağıda örnek bir çözüm verilmiştir.

YT, Çok Düşük ise YSA $\rightarrow$ Çok Düşük

YT, Düşük ise YSA $\rightarrow$ Düşük

YT, Orta ise YSA $\rightarrow$ Düşük

YT, Yüksek ise YSA $\rightarrow$ Orta 
YT, Çok Yüksek ise YSA $\rightarrow$ Orta

Yeşil tasarımın artması yeşil satın almayı aynı seviyede artırmadığı için uzmanın bu konudaki yorumu 'pozitif orta' şeklinde olmuştur.

1.Uzman: Pozitif Güçlü

2.Uzman: Pozitif Güçlü

3.Uzman: Pozitif Çok Güçlü

şeklinde yorum yapmıș olursa șekil 4'de gösterildiği gibi (Koyu renk olan doğrusal çizgi iki uzmanın aynı yorumu yaptığını göstermektedir) ağırlıklı ortalama yöntemi kullanılarak etkileşim ağırlı $\breve{g} ı$ hesaplanır.

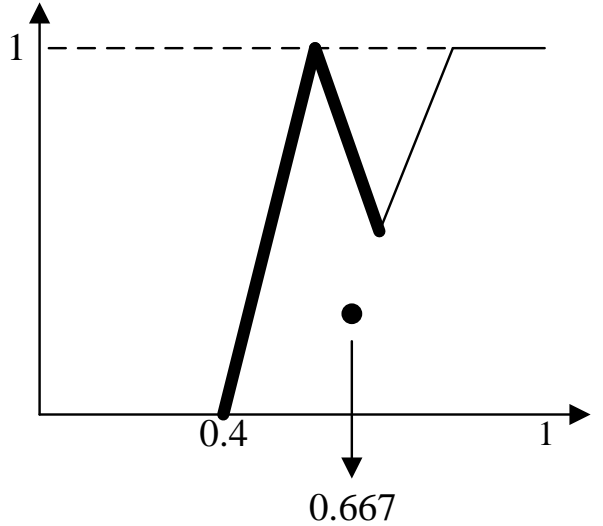

Şekil 4. Ağırlıklı Ortalama Yöntemi İle Etki Hesaplama

Tablo 3. Konseptler Arasındaki İlişki Matrisi

\begin{tabular}{ccccccccccc}
\hline $\mathbf{W}_{\mathrm{ij}}$ & $\mathrm{C} 1$ & $\mathrm{C} 2$ & $\mathrm{C} 3$ & $\mathrm{C} 4$ & $\mathrm{C} 5$ & $\mathrm{C} 6$ & $\mathrm{C} 7$ & $\mathrm{C} 8$ & $\mathrm{C} 9$ & $\mathrm{C} 10$ \\
\hline $\mathrm{C} 1$ & 0 & 0.467 & 0 & 0.6 & 0 & 0 & 0 & 0 & 0 & 0.667 \\
$\mathrm{C} 2$ & 0.4 & 0 & 0 & 0.533 & 0.6 & 0 & 0 & 0 & 0 & 0.6 \\
$\mathrm{C} 3$ & 0 & 0 & 0 & 0 & 0.733 & 0 & 0.867 & 0.8 & 0 & 0.733 \\
$\mathrm{C} 4$ & 0 & 0.667 & 0.467 & 0 & 0.733 & 0 & 0 & 0.733 & 0 & 0.8 \\
$\mathrm{C} 5$ & 0.467 & & 0.667 & 0.6 & 0 & 0 & 0 & 0.8 & 0 & 0.8 \\
$\mathrm{C} 6$ & -0.533 & -0.4 & -0.333 & -0.733 & -0.733 & 0 & -0.667 & -0.8 & 0 & -0.6 \\
$\mathrm{C} 7$ & 0.533 & 0.533 & 0.8 & 0.6 & 0.8 & 0 & 0 & 0.467 & 0 & 0.8 \\
$\mathrm{C} 8$ & 0.333 & & 0.733 & 0.533 & 0.333 & 0 & 0.467 & 0 & 0 & 0.667 \\
$\mathrm{C} 9$ & -0.533 & -0.4 & -0.4 & -0.733 & -0.567 & 0.467 & -0.6 & -0.733 & 0 & -0.667 \\
$\mathrm{C} 10$ & 0 & 0 & 0 & 0 & 0 & 0 & 0 & 0 & 0 & 0 \\
\hline
\end{tabular}

Ağırlıklar hesaplandıktan sonra. üç adet senaryo yeşil tedarik zinciri yönetimi performansı açısından BBH kullanılarak değerlendirilmiştir. Uzmanlar yeşil tedarik zinciri yönetimi konusunda çalışan iki akademisyen ve 1 EFQM (Avrupa Kalite Yönetimi Vakfi) değerlendiricisinden oluşmaktadır. İterasyonlar uzmanlar tarafindan oybirliği ile belirlenen 1 yıllık süreci ifade etmektedir. Mevcut durum vektörünün bulunmasında uzman görüşleri kullanılmış ve konseptlerin özelliklerine göre yapılan değerlendirmeler ile $\mathrm{A}^{(\mathrm{k})}$ vektörü hesaplanmıştır.

Senaryo 1: Uzmanların değerlendirmesi sonucunda yeşil tasarım. yeșil satın alma. yeşil üretim. yeşil pazarlama. yönetmeliklerin bilinmemesi ve yeşil tedarik zinciri yönetimi düşük. yeşil lojistik orta. tersine lojistik. karbon yönetimi. gelenekselci yaklaşımın ise yüksek değerler aldığı düşünülmüştür. Gelenekselci yaklaşım ve yönetmeliklerin bilinmemesi çıktı konsepti olan
YTZY performansını ve diğer konseptleri kötü etkileyeceğinden yüksek değerler olması istenmeyen bir durumdur. 1. senaryoya ait A(başlangıç vektörü) aşağıdaki gibidir:

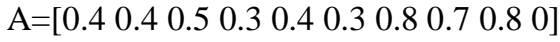

Gelenekselci yaklaşım. hiçbir konseptten etkilenmeyip hepsine negatif etki etmektedir. Denklem (1) ve (2) uygulandıktan sonra model için elde edilen grafik Şekil 5 'teki gibidir. Yeșil üretime ve diğer düşük konseptlere bu senaryo içerisinde daha fazla önem gösterildiğinde. yeşil tedarik zinciri yönetimi konusunda daha iyi bir seviye beklenebilir. Mevcut durumdaki konseptlerin başlangıç vektöründeki belirtildiği gibi yönetilmesiyle YTZY performans1 8. iterasyonda maksimum değerini almasina rağmen. diğer konseptlerin kötü yönetilmesiyle 16. iterasyonda en kötü seviyede kararlı duruma ulaşacaktır. 


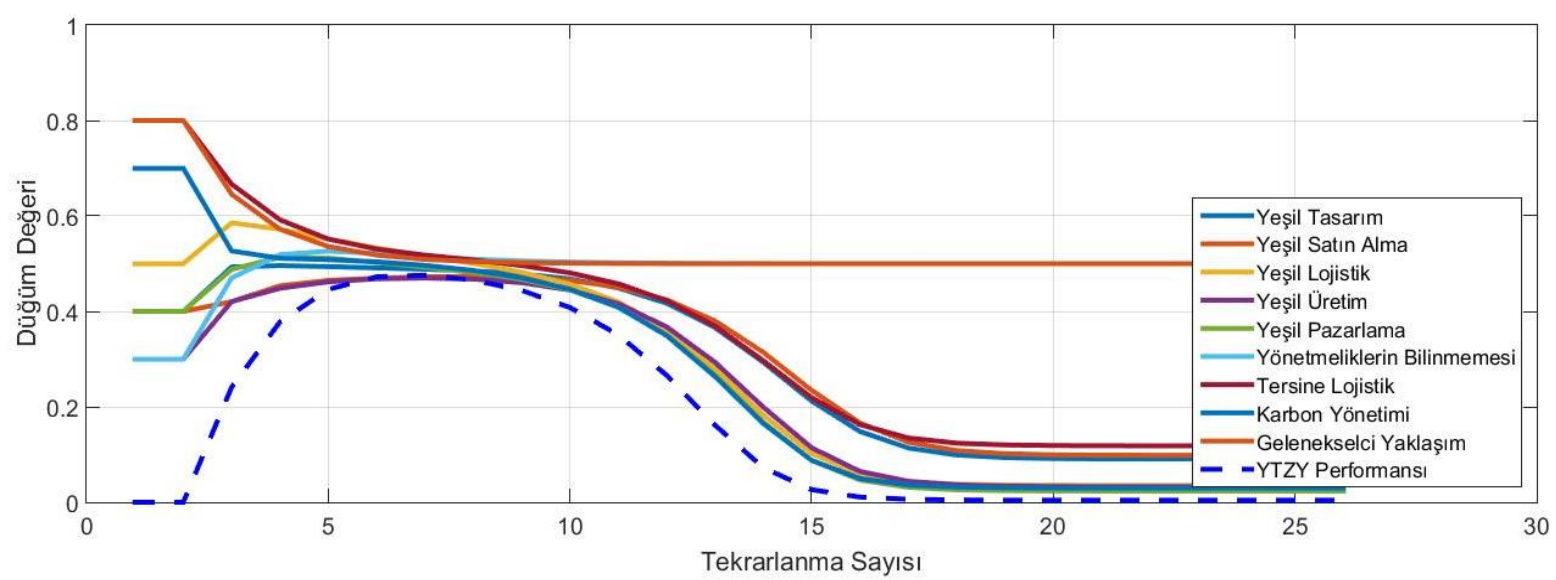

Şekil 5. 1. Senaryonun YTZY Analizi

Senaryo 2: 2 . senaryoda uzmanların değerlendirmesi sonucunda yeşil tasarım. yeşil lojistik. yeşil üretim. yeşil pazarlama. tersine lojistik konseptlerinin yüksek; yeşil satın alma ve yeşil tedarik zinciri yönetiminin orta; yönetmeliklerin bilinmemesi. karbon yönetimi ve gelenekselci yaklaşımdan düşük değerler aldığ 1 düşünülmüştür. 2. senaryoya ait A matrisi aşağıdaki gibidir.

\section{$\mathrm{A}=\left[\begin{array}{llllllllll}0.6 & 0.5 & 0.7 & 0.9 & 0.6 & 0.3 & 0.7 & 0.4 & 0.1 & 0\end{array}\right]$}

$\mathrm{Bu}$ değerler Denklem (1) ve (2)'ye sırasıyla verildikten sonra Şekil 6'daki sonuç elde edilmiştir. Yeşil üretim oldukça iyi bir seviyededir; bu YTZY için istenen bir durumdur. Gelenekselci yaklaşım ve yönetmeliklerin bilinmemesi bu senaryoda oldukça düşük değerler almıştır. $\mathrm{Bu}$ yeşil tedarik zinciri yönetimi için olumlu bir durumdur çünkü gelenekselci yaklaşım ve yönetmeliklerin bilinmemesi yeşil tedarik zinciri yönetimini ve diğer tüm konseptleri olumsuz yönde etkilemektedir. Yeşil üretim ve yeşil pazarlama da ortalamanın üstünde bir seviyededir. Grafikten de anlaşıldığı gibi iyi yönetilen konseptler sonucunda YTZY performansı mükemmellik seviyesine 4 iterasyon sonunda ulaşmıştır. Bu senaryoda incelen organizasyonda. gelenekselci yaklaşım ve yönetmeliklerin bilinememe durumu artış gösterse de. diğer tüm konseptlerin iyi yönetilmesi YTZY performansını iyi seviyeye getirmektedir.

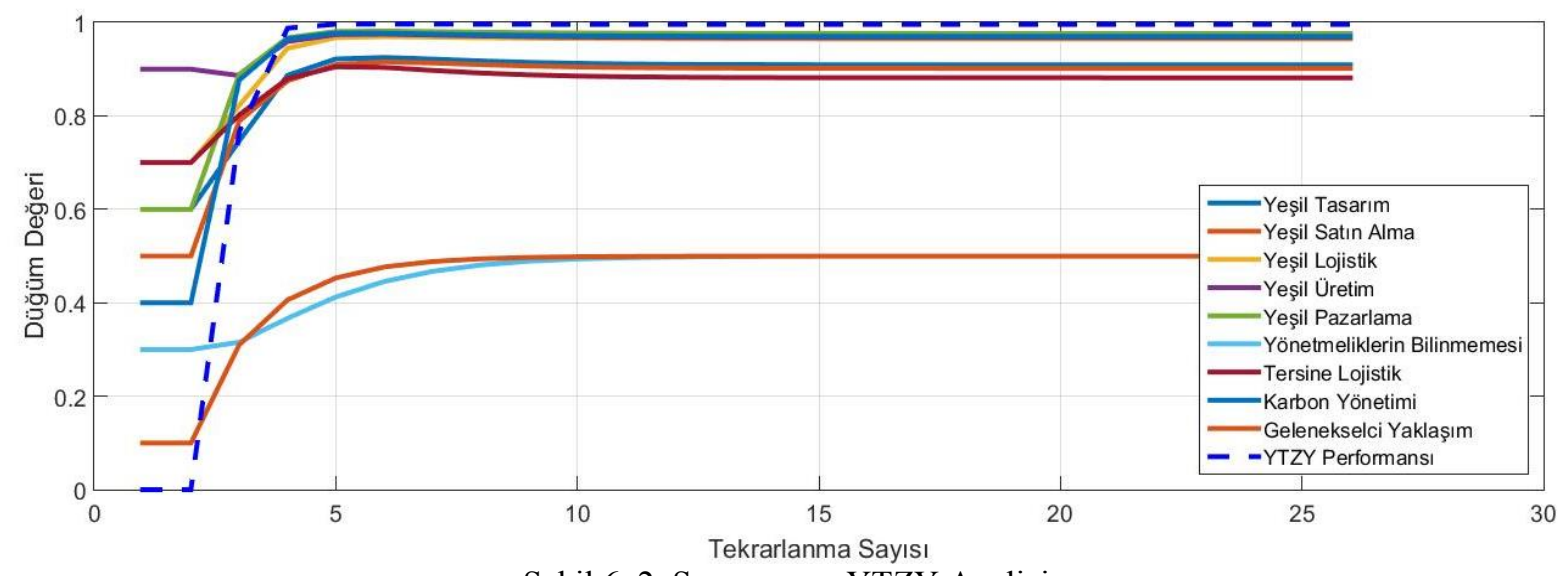

Şekil 6. 2. Senaryonun YTZY Analizi

Senaryo 3: 3. senaryoda uzmanların değerlendirmesi sonucunda gelenekselci yaklaşım ve yönetmeliklerin bilinmemesi konseptlerinin oldukça yüksek ve diğer konseptlerin de iyi yönetilmediği düşünülmüştür. 3 . senaryoya ait A matrisi aşağıdaki gibidir.

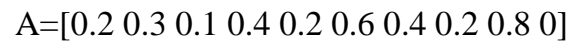

$\mathrm{Bu}$ değerler algoritmaya girildikten sonra Şekil 7 'deki grafik elde edilmiştir.
Yeşil tedarik zinciri yönetimi uygulamalarından hiçbirine gerekli değeri göstermemiş olarak düşünülen senaryoda. bu şekilde devam ederse hiçbir zaman yeşil tedarik zinciri yönetimi konusunda iyi bir yere gelemeyeceği kanısına varılmıştır. Yeşil tedarik zinciri yönetimi ilk 2 iterasyonda biraz artış gösterip sonrasında hızlı bir düşüş göstermiştir. Bu çalışmada gözlemlenen en kötü senaryo bu senaryo olmuştur. 


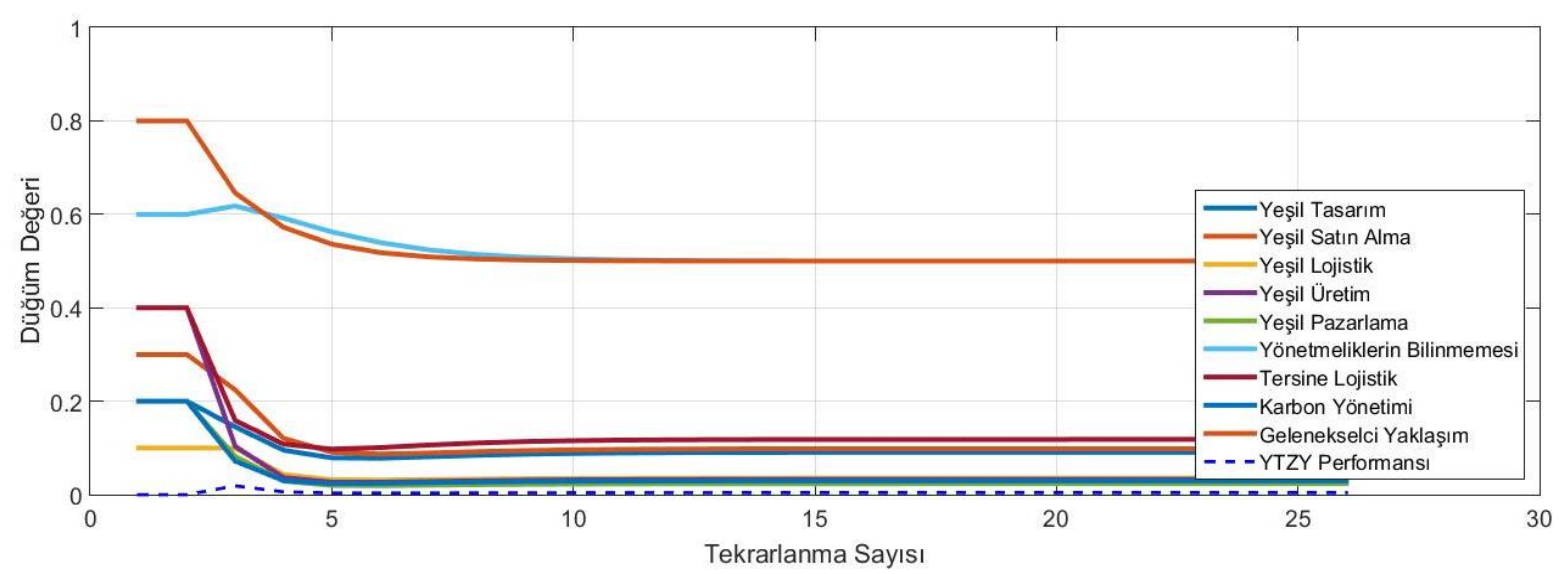

Şekil 7. 3. Senaryonun YTZY Analizi

\section{ANALIZ}

Merkeziyet derecesi birbiriyle olan ilişkilerden yola çıkarak bir sistemde konseptlerin önem derecelerini tespit etmek için kullanılan bir hesaplamadır. Merkeziyet derecesi hesaplanırken ilişki haritasında konseptler arasındaki negatif ya da pozitif değerlerin her biri kendi içinde toplanır ve kendi merkeziyet derecelerini oluştururlar. Örneğin C1 için merkeziyet derecesi hesaplanırken ilişki haritasından hangi konseptlerle ilişki içerisinde olduğuna bakılıp her ilişkinin ağırlığ değerlendirmesi sonucunda oluşan ağırlıklardan çekilir ve toplanır. C1'in merkeziyet derecesi bu şekilde belirlenmiş olmaktadır. Bu işlem bütün

konseptlere uygulandığından aşağıdaki değerler elde edilmektedir.

Örneğin $\mathrm{C} 1$ için; toplam etkiyi görebilmek için negatif ya da pozitif tüm ilişkiler mutlak değer olarak toplanır.

\section{Merkeziyet Derecesi ${ }_{\mathrm{C} 1}=\left|\mathrm{C} 1 \_\mathrm{C} 2\right|+\mid \mathrm{C} 1$ C4|+|C1_C10|+|C2_C1 $1+\left|\mathrm{C} 5 \_C 1\right|+\left|\mathrm{C} 6 \_\mathrm{C} 1\right|+\left|\mathrm{C} 7 \_\mathrm{C} 1\right|$ $+\left|\mathrm{C} 8 \_\mathrm{C} 1\right|+\left|\mathrm{C} 9 \_\mathrm{C} 1\right|$}

Merkeziyet Derecesi $\mathrm{C}_{1}=|0.467|+|0.6|+|0.667|+$ $|0.4|+|0.467|+|-0.533|+|0.533|+|0.333|+|-0.533|$ $=4.533$

Tablo 4. Merkeziyet Derecesine Göre Konseptlerin Önem Siralaması

\begin{tabular}{cc}
\hline Konsept İsmi & Önem Derecesi \\
\hline Yeşil Tasarım & 4.533 \\
Yeşil Satın Alma & 4.6 \\
Yeşil Lojistik & 6.533 \\
Yeşil Üretim & 7.732 \\
Yeşil Pazarlama & 7.833 \\
Yönetmeliklerin & 5.266 \\
Bilinmemesi & \\
Tersine Lojistik & 7.134 \\
Karbon Yönetimi & 7.399
\end{tabular}

Gelenekselci Yaklaşım

5.1

Elde edilen değerlere göre yeşil tedarik zinciri yönetimi için en etkili konseptin 7.833 değerine sahip olan yeşil pazarlama olduğu gözükmektedir. En az etkili konsept ise en küçük değere sahip olan yeşil tasarım konseptidir. Elde edilen sonuç. yeşil pazarlama konseptindeki değişimin YTZY performansını diğer konseptlere göre daha fazla etkileyeceğini göstermektedir. Aynı mantıkla analiz sonucu en az etkili konsept olduğu belirlenen yeşil tasarımdaki değişim ise YTZY'yi diğer konseptlere göre daha az etkileyeceği yorumu yapilabilmektedir.

\section{SONUÇ}

Yeşil tedarik zinciri yönetimi son zamanlarda kuruluşlar için önem kazanıp önemli bir rekabet konusu haline gelmiştir. Çevreye duyarlılığın artması sonucunda müşterilerin talepleri de bu yönde değişmiştir. $\mathrm{Bu}$ sebeple kuruluşların yeşil tedarik zinciri yönetimini uygulamaları hem kendi verimliliklerini hem de tercih edilme oranlarını artırır. Yeşil tedarik zinciri yönetimi uygulayan kuruluşların bu konuda ne durumda olduklarını tespit edebilecekleri ve ne zaman istenilen seviyeye ulaşacaklarını öğrenebilecekleri; kısaca YTZY konusunda yol gösterici sayısal bir çalışma bulunmamaktadır.

$\mathrm{Bu}$ çalışmanın amacı belirlenen uzmanlar tarafından belirlenen senaryoları yeşil tedarik zinciri yönetimi açısından değerlendirmek ve ne kadar süre sonra dengeye ulaşacaklarını belirlemektir. $\mathrm{Bu}$ karmaşı yapının çözümlenebilmesi için bulanık bilişsel haritalar yönteminden faydalanılmıştır.

Bu çalışmada üç farklı senaryo yeşil tedarik zinciri yönetimi açısından değerlendirilmiştir. Değerlendirmeler sonucunda 2 . senaryonun dengeye ulaşıp. YTZY açısından istenilen duruma geleceği görülmüştür. Bunun sebebi olarak da 
mevcut YTZY ve analize göre de en önemli çıkan yeşil pazarlama değerinin daha yüksek olması gösterilebilir. Bunun yanında YTZY'ye negatif etkisi olan gelenekselci yaklaşım konseptinin de 1 . senaryoya göre oldukça düşük değerde olmasıdır. 3. senaryoda ise YTZY performansının çok kötü bir durumda olduğu görülmüş ve bu şekilde devam ederse hiçbir zaman YTZY'nde iyi bir konuma gelemeyeceği kanısına varılmıştır.

Çalışmada YTZY performansı konusunda mantıklı sonuçların elde edilmesi ve geleceğe yönelik öngörü kazanılması sağlamıştır. Ölçülmesi ve öngörü sahibi olunması oldukça güç olan YTZY performansının Bulanık Bilişsel Haritalama yöntemiyle değerlendirilmesi ile organizasyonlar için teşvik edici sonuçlar elde edilmiştir. Gelecekteki çalışmalarda. uzmanların modelin haritasını oluştururken oybirliği sürecini ortadan kaldırmak için çok kriterli karar verme tekniklerinin kullanılması umut verici olarak görülmektedir.

\section{KAYNAKÇA}

[1] H. M. Akıncı. "Bulanık Bilişsel Haritalar Yardımıyla İnsan Duygularının Modellenmesi." Thesis. Fen Bilimleri Enstitüsü. 2013.

[2] Martha C. Cooper, Lisa M. Ellram, "Characteristics Of Supply Chain Management \& The Implications For Purchasing \& Logistics Strategy". Vol. 4. No. 2. 1993.

[3] G. Erdem. "Tedarik Zinciri Yönetimi Uygulamalarının Benimsenmesinin. Tedarik Zinciri Ve İşletme Performansına Etkisi.” 2013.

[4] H. Min And W. P. Galle. "Green Purchasing Practices Of Us Firms." Int. J. Oper. Prod. Manag.. Vol. 21. No. 9. Pp. 1222-1238. Sep. 2001.

[5] Büyüközkan. G. . Ardaloğlu. Z.. "Yeşil Tedarik Zinciri Yönetimi.” Lojistij Derg.. Vol. 8. No. 66-73. 2008.

[6] H. B. Bolat. D. Bayraktar. M. Öztürk. And N. Turan. "Yeşil Lojistik Zincirinde Araç Rotalama Problemi İçin Bir Model Önerisi.” Jun. 2011.

[7] G. Nakiboğlu. "Tersine Lojistik: Önemi Ve Dünyadaki Uygulamaları.” Iktis.Ve İdari Bilim. Fakültesi Derg.. Vol. 9. No. 2. Pp. 1-16. 2007.

[8] B. Kosko. "Fuzzy Cognitive Maps." Int. J. Man-Mach. Stud.. Vol. 24. No. 1. Pp. 65-75. 1986.

[9] E. I. Papageorgiou. A. T. Markinos. And T. A. Gemtos. "Fuzzy Cognitive Map Based Approach For Predicting Yield In Cotton Crop Production As A Basis For Decision Support System In Precision Agriculture Application.” Appl. Soft Comput.. Vol. 11. No. 4. Pp. 3643-3657. 2011.
[10] Nikas, A., Doukas, H., "Developing Robust Climate Policies: A Fuzzy Cognitive Map Approach" Operations Research \& Management Science. Springer International Publishing, Pp. 239-263. 2016

[11] Amirkhani, A., Papageorgiou, E.I., Mohseni, A., Mosavi, M.R. "A Review Of Fuzzy Cognitive Maps In Medicine: Taxonomy, Methods, And Applications." Comput. Methods Programs Biomed. 142, 129-145. 2017.

[12] Sarabai, D.T., Arthi, K., "Efficient Breast Cancer Classification Using Improved Fuzzy Cognitive Maps With Csonn.” Int. J. Appl. Eng. Res. 11, 2478-2485. 2016.

[13] Subramanian, J., Karmegam, A., Papageorgiou, E., Papandrianos, N., Vasukie, A.,. "An Integrated Breast Cancer Risk Assessment And Management Model Based On Fuzzy Cognitive Maps." Comput. Methods Programs Biomed. 118, 280-297. 2015.

[14] Chen, C.T., Chiu, Y.T., "A Study Of Fuzzy Cognitive Map Model With Dynamic Adjustment Method For The Interaction Weights." International Conference On Advanced Materials For Science And Engineering (Icamse), Pp. 699-702. 2016.

[15] Case, D.M., Stylios, C.D., "Fuzzy Cognitive Map To Model Project Management Problems." Annual Conference Of The North American Fuzzy Information Processing Society (Nafips), Pp. 1-6. 2016.

[16] Ribeiro, M.I.F., Ferreira, F.A.F., Jalali, M.S., Meidute-Kavaliauskienè, I., "A Fuzzy KnowledgeBased Framework For Risk Assessment Of Residential Real Estate Investments." Technol. Econ. Dev. Econ. 23, 140-156. 2017.

[17] Cano Marchal, P., Garcia, J.G., Ortega, J.G., "Application Of Fuzzy Cognitive Maps And RunTo-Run Control To A Decision Support System For Global Set-Point Determination." Ieee Trans. Syst. Man Cybern. Syst. 1-12. 2017.

[18] Peter, G.P., Antigoni, A.P., Vasileios, G.P., "A New Mathematical Modelling Approach For Viticulture And Winemaking Using Fuzzy Cognitive Maps." Ifac-Pap., 16th Ifac Conference On Technology, Culture And International Stability Tecis 2015 48, 15-20. 2015.

[19] Pacilly, F.C.A., Groot, J.C.J., Hofstede, G.J., Schaap, B.F., Bueren, E.T.L. Van, "Analysing Potato Late Blight Control As A Social-Ecological System Using Fuzzy Cognitive Mapping." Agron. Sustain. Dev. 36, 35. 2016.

[20] P. P. Groumpos. "Fuzzy Cognitive Maps: Basic Theories And Their Application To Complex Systems." In Fuzzy Cognitive Maps.” M. Glykas. Ed. Springer Berlin Heidelberg. Pp. 1-22. 2010. 